\title{
Dr. Mirta Roses Periago leads PAHO in the Millennium ${ }^{1}$
}

Like all staff of the World Health Organization and the Pan American Health Organization, when I began my work almost 20 years ago I made a commitment to serve the Organization. At this time I am reaffirming that commitment with emotion and pride at being the first woman to become Director of this prestigious, century-old Organization and to take responsibility for leading it into the new millennium.

I feel moved by a force like a raging torrent, as Maya Angelou would say, that propels me forward. It is the coming together of the deferred dreams and aspirations of generations of women, public health workers, struggling people filled with hope in search of a better quality of life for themselves and future generations.

The great challenge is to fulfill these expectations, but the presence here of you, my dear old colleagues and friends who have come from far off, my family, my fellow workers, the representatives of governments, professional agencies, and civil organizations, and all who are viewing us on screen, clearly symbolizes your recognition of the importance of health for our peoples and your respect for this Organization. It also means that I will have with me a marvelous team with which to study, debate, identify, and select the best strategies and actions for moving quickly to attain a better quality of life for all the peoples of the Americas.

I appreciate the kind remarks of the Representative of the Organization of American States (OAS), the Department of Health and Human Services of the United States, and the Minister of Health of Ecuador, who spoke for all the countries of the Americas, as well as the message delivered by Dr. Gro Harlem Brundtland [Director of the World Health Organization] and the very special words of our Director Emeritus, Sir George Alleyne.

Since the last Pan American Sanitary Conference was held in September, 2002, I have received countless congratulatory messages, offers of collaboration, invitations to visit the countries, proposals for joint efforts. I would like to thank you all collectively and to assure you that it is my greatest wish to establish close contact as soon as possible with all the countries in our hemisphere. I shall focus on working in and with the countries and, faithful to my calling as an epidemiologist, I will work hard at remaining in close touch with communities and observing the projects under way where the action takes place.

This children's chorus ${ }^{2}$ is like a delegation representing the millions of boys and girls in our countries. At this swearing-in ceremony, their voices bring home the fact that they are the concrete targets of our work and that our task must be to guarantee them the best opportunities in life.

The PAHO choir ${ }^{3}$ represents the voices of our staff and of all public health workers in our hemisphere, who are always willing to give generously of themselves to promote health and protect life.

The six directors who preceded me at PAHO forged a path of excellence and transparency in this house. All of them worked to build a frugal, prudent institution that protects its human resources and the storehouse of knowledge amassed by all

\footnotetext{
1 This speech was pronounced at the Headquarters of the Pan American Health Organization (PAHO) in Washington, D.C., on 31 January 2003, when Dr. Roses Periago took over as Director of the Pan American Sanitary Bureau (PSB), PAHO's executive body. The Pan American Health Organization, which is also the Regional Office of the World Health Organization for the Americas, is composed of 35 Member States, three Participating Governments, one Associate Member, and two Observers.

2 The Director is referring to a choir of local schoolchildren who sang at the event.

3 The Director is referring to PAHO's institutional choir.
} 
the countries.

The Organization has a solid foundation: the health workers in the Secretariat and the countries who have passionately worked to meet the goals established for improving health; the ministers and leaders in health who have guided the joint action to ensure success; and the partners and affiliates who have generously given their support and have entrusted us with the financial resources and technology with which to meet the proposed objectives. With this united group bound in solidarity, we have made great strides in public health and improved the health status of our peoples, even in the midst of serious political, economic, and social crises.

This will be the century of networks, connectivity and interdependence, and all of these will enable us to overcome the barriers of space and time and to open up heretofore unimaginable possibilities for humanity. If we use these networks to multiply exponentially the social capital available, to link people and institutions in a vast web of support that embraces all the inhabitants of our hemisphere, we will have taken a giant step toward ensuring that our knowledge and experience converge into finding new modes of exchanging technical cooperation for sustainable human development.

Countless service, teaching, and research institutions, as well as those that generate health-related resources, will make up the networks that will carry out the tasks on which my administration will focus. The potential of existing resources and the interest in health and development activities are so evident today that we will be in the best position possible to develop new programs that are both useful and relevant to all the countries. Several working groups are already engaged in preliminary consultations to promote these lines of action. Information exchange and cooperation among countries and institutions are the essence of PAHO's work. We will launch a Health in the Americas portal as a virtual village marketplace, where all actors concerned with promoting public health can come together.

We are committed to health for all, to the primary care strategy, to health promotion, and to reducing inequities and social exclusion. We defend the principles of technical cooperation for capacity building and for guaranteeing self-sufficiency, autonomy, excellence, and sustainability. We are convinced that the experiences and methodologies that emerge-often with enormous creativity, as shown in Argentina-under the most adverse conditions, during the most trying times, and in the poorest and most disadvantaged areas represent valuable capital that PAHO should take advantage of, systematize, and place within the grasp of all as an important tool for improvement and development.

The past century has witnessed significant achievements in health in the Americas and deserves celebration. Working together in solidarity, PAHO and its Member States have recorded and properly commemorated this centennial. We entered the new century with a gradual improvement in our health indicators. We must now keep our eye on the challenges that demand greater attention so that together we can face them successfully and hasten the attainment of the best possible health for all.

The countries of the Region face poor economic conditions marked by increasing poverty, aging populations, chaotic urban growth at an accelerated pace, and environmental degradation, all of which render them highly vulnerable. Every day more people are living below the poverty line, and the gap between the rich and poor is widening in many countries, communities, and social groups. Environmental risks grow more threatening day by day, and globalization is producing unequal benefits that exacerbate the inequities among countries.

Within this context, those of us who consider health a social good can take pride in having been able to make and sustain impressive gains in public health and in increased life expectancy in most countries, despite successive, prolonged economic and political crises. We have experienced extremely difficult periods, such as 
the so-called "lost decade" with its setbacks for democracy and its economic stagnation, but we have still managed to eliminate polio, make measles virtually disappear, and reduce infant mortality.

Nevertheless, the growing threat of HIV, AIDS, malaria, dengue, violence, chronic diseases, and mental and physical disabilities is disturbing. In keeping with the Strategic Plan, during my mandate I shall focus on containing the AIDS epidemic, with special emphasis on Caribbean countries, and to improving health conditions in priority countries, especially Haiti.

The above are general guidelines that will enable us to focus PAHO's work in the coming years. The Strategic Plan now requires that ideas be transformed into concrete courses of action, organizational arrangements, and programs that are geared to every country's particular situation.

Health disparities are increasingly associated with social vulnerability, unstable economic growth, and threats to national security. Governments and other key sectors are acutely aware of the need to reduce the gaps in health status and in access to health services. At the same time, regional integration processes are focusing more on the international dimensions of public health and its close links with national and local conditions.

The goals expressed in the Millenium Declaration reflect an unprecedented political consensus on the state of the world and a vision for the future, setting measurable goals and specific timetables for human progress. These goals are attainable as long as we are able to turn them into the banner, the dream, the aspiration, and the demands of individual people, groups, families, communities, and nations. They are attainable if we can generate enthusiasm and muster the individual and joint efforts of multiple networks of people speaking different languages, beliefs, and realities, and if we can revive trust, understanding, and solidarity among the countries.

The health sector will bear a heavy responsibility in attaining the goals of the millennium and expects to benefit in turn from the progress resulting from consensus-building among all sectors. Since the Declaration of Health for All and the conference on primary care that was held in Alma-Ata 25 years ago, the world has not heard a call to collective action with as powerful a message.

I am committed myself to taking the first steps toward creating a new model of collective action for PAHO in the twenty-first century, one that will allow each human group to define its own goals, attainments, and intermediate objectives and to perform its own social surveillance so as to ensure that these are met as swiftly as possible. Imbued with hope and determination, we are going to sweep all of society, as well as all our friends and allies in the hemisphere, in a tidal wave of optimism and resolve to meet those goals. We will forge the great team for Health in the Americas by building on the successes and experiences amassed under the banner of Health for All, acknowledging our mistakes and failures, our weaknesses and strengths, and also our valuable contributions to the well-being and progress of human society.

We have made strides in recognizing the economic value of health, its immeasurable contribution to reducing poverty and attaining more just and sustainable human development, thereby contributing to human security, the advancement of participatory democracy, and economic growth in harmony with nature, without compromising the survival of future generations. Our societies demand that in allocating resources, priority be given to protecting and improving the health of our populations. They view this as a wise and intelligent decision that makes political authorities legitimate leaders in the public eye.

I am convinced that this is the time for the health of our peoples to become a driving force for the achievement of social stability and economic growth, enriching human and social capital and imbuing it with dignity. The time is ripe for putting health at the forefront of social action and taking advantage of its undeniable contribution to the reduction of social and economic inequities. Health can mobilize all of society to obtain rapid, sustainable human develop- 
ment in our hemisphere.

I therefore intend:

- to restore the Pan American Health Organization as the forum for health in the Americas and to open it to the participation of all sectors of society;

- to work toward building consensus and forging partnerships, strengthening hemispheric and global solidarity, and encouraging new social actors to become involved in efforts to promote health;

- to address the new dimensions of health within the hemisphere's economic, social, and political integration processes;

- to advocate the continuous improvement of health systems, promoting rapid advances in securing geographical, cultural, and financial access to health services and expanding social protection, in keeping with the mandates of the summits of presidents and heads of state and government;

- to restore the pride and commitment of health workers and health organizations, emphasizing the importance of quality care and accountability, with practices based on shared and accepted evidence;

- to make PAHO the public reference center for health information, utilizing and facilitating access to knowledge with all the instruments at its disposal within the framework of the electronic revolution and mass communications.

My predecessors, and especially Sir George, now Director Emeritus of PAHO, have turned over to us this day a youthful centenarian PAHO. We have a beautiful renovated Headquarters and many refurbished, well-maintained Representative Offices in the countries, as well as a corps of highly committed, welltrained professionals and support staff. Thanks to prudent and skillful financial management, we can cooperate with the countries on a continuous basis, but we will be able do far more if they increase our resources. I would like to thank you, Dr. Alleyne, in the name of all your friends in this house, for your skill and leadership, your affection and zealous commitment to PAHO in every year in which you served as a staff member or as Director. As Dr. Barry Whaley [former PAHO/WHO Representative in the Bahamas and Venezuela) said at a recent meeting of former PAHO staff, "You can take the staff member out of PAHO, but you can't take PAHO out of the staff member." As proof of that, we have here with us two former ministers of Ecuador who, in collaboration with several others, put together a very beautiful book to mark the Organization's centennial.

My first paying job with the Ministry of Health was as a door-to-door vaccinator during the vaccination campaign of 1965 , when we were eradicating smallpox. I feel very moved and privileged, after 38 years, to remain a public servant committed to health in the Americas and to pay homage to volunteer and community health workers on this, the 25th anniversary of the Alma-Ata conference.

And I assure you, Cacique Mario in Tartagal, Argentina; Father Tarcisio in Gutierrez, Bolivia; Carlos Osorio, President of Villa Centenario in Acajutla, El Salvador; Ma Pampo and the centenarian ladies of Dominica; and the women of the assembly plants and neighborhoods on the Mexico-U.S. border, that this Director and this team at PAHO will be united in the defense of your health and your future.

I would like to close my remarks with some words from a poem by Leon Felipe, a Spanish writer who sought refuge in Mexico during the civil war:

$$
\begin{gathered}
\text { I ride with the reins taut, } \\
\text { holding back, } \\
\text { for the important thing } \\
\text { is not to arrive alone } \\
\text { or even first, } \\
\text { but together and on time. }
\end{gathered}
$$

Thank you very much, and now, let's get back to work! 